\title{
O IMPACTO DA NOVA ESTAÇÃO DE TRATAMENTO DE EFLUENTES DO MUNICÍPIO DE RESENDE-RJ PARA O FORTALECIMENTO DO CONCEITO DE CIDADE SUSTENTÁVEL
}

\author{
Randal Magnani* \\ Eduardo da Silva Lima**
}

\section{RESUMO}

$\mathrm{O}$ artigo visa demonstrar a necessidade de se implementar políticas públicas no intuito da recuperação das fontes de água potável. Será demonstrado o conceito de cidade sustentável, no que se refere ao uso da água e seu devido tratamento. Buscou-se apresentar a situação particular da cidade de Resende-RJ, que tem se destacado em matéria de tratamento de efluentes em âmbito nacional, demonstrando sua preocupação com o meio ambiente e a sustentabilidade. O método empregado para o trabalho foi o da pesquisa por meio de coleta de dados e pesquisa bibliográfica.

Palavras-chave: Meio ambiente. Cidade sustentável. Água. Saneamento básico. Estação de Tratamento de Efluentes.

\section{THE IMPACT OF THE NEW EFFLUENT TREATMENT PLANT IN THE MUNICIPALITY OF RESENDE-RJ FOR THE STRENGTHENING OF THE CONCEPT OF SUSTAINABLE CITY}

\begin{abstract}
The article aims to demonstrate the need to implement public policies for the recovery of drinking water sources. The concept of sustainable city will be demonstrated with regard to the use of water and its due treatment. It was tried to present the particular situation of the city of Resende-RJ, which has stood out in terms of effluent treatment at a national level, demonstrating its concern with the environment and sustainability. The method used was the research through data collection and bibliographic research.
\end{abstract}

Key words: Environment. Sustainable city. Water. Basic sanitation. Effluent treatment plant.

\section{INTRODUÇÃO}

Neste trabalho científico será abordada a questão da água e seu devido tratamento como fonte de uma cidade sustentável, bem como as condições em que deve ser devolvida ao meio ambiente. A história da humanidade mostra que as cidades sempre nasceram próximas

\footnotetext{
*Mestre em Direito - Centro Universitário Salesiano de São Paulo (UNISAL) - Lorena-SP. Mestre em Ciências Militares - Escola de Aperfeiçoamento de Oficiais (EsAO) - Rio de Janeiro - RJ. Professor da Cadeira de Direito da Academia Militar das Agulhas Negras (AMAN) - Resende-RJ e Professor do Curso de Direito da Universidade Estácio de Sá, Campus Resende-RJ. randalmagnani@yahoo.com.br.

*** Mestre em Direito pelo Centro Universitário Salesiano de São Paulo (UNISAL) - Lorena (SP). Pós-graduado em Direito do Estado pela Universidade Estácio de Sá (RJ). Professor da Cadeira de Direito da Academia Militar das Agulhas Negras (AMAN) - Resende-RJ. prof.eduardolima@gmail.com.
} 
de um curso d'água, buscando água potável a montante e despejando seus efluentes a jusante. Todas as cidades repetem este mesmo modelo de coleta e despejo de efluentes, no entanto, com o crescimento populacional e, consequentemente, das cidades, aumenta-se a quantidade de esgotos despejados nos rios e surge a necessidade do tratamento adequado a fim de preservar as bacias hidrográficas.

Buscará demonstrar quais as consequências para a população da cidade de Resende, sul do estado do Rio de Janeiro, com a entrada em funcionamento da nova estação de tratamento de esgoto, a ETE/AMAN, que elevou a capacidade de tratamento de efluentes do município.

Por fim, será apresentado como era e como está o tratamento de efluentes da cidade em questão, e como está buscando melhorar os índices até atingir seu objetivo final, qual seja, o tratamento de $100 \%$ do esgoto gerado por seus habitantes, em prol de uma cidade sustentável e sempre preocupada com a preservação do meio ambiente para a presente e futuras gerações.

\section{Os índios americanos e a consciência ecológica}

Em 1854, o presidente dos EUA ofereceu aos índios uma troca de terras indígenas por outras num local remoto daquele país. Esta foi, com certeza, a resposta mais clara ao que pode ser chamada de ecologia e pureza do meio ambiente. O Chefe indígena Seattle, em sua carta ao presidente norte-americano, disse que o homem branco consegue, com seu modo de viver, destruir tudo aquilo que usa sem se preocupar com a natureza.

\footnotetext{
Sabemos que o homem branco não compreende o nosso modo de viver. Para ele, um torrão de terra é igual ao outro. Porque ele é um estranho que vem de noite e rouba da terra tudo quanto necessita. A terra não é sua irmã, nem sua amiga, e, depois de exauri-la, vai embora. Deixa para trás o túmulo de seu pai sem remorsos. Rouba a terra de seus filhos, nada respeita. Esquece os antepassados e os direitos dos filhos. Sua ganância empobrece a terra e deixa atrás de si os desertos. Suas cidades são um tormento para os olhos do homem vermelho, mas talvez seja assim, por ser o homem vermelho um selvagem, que nada compreende (CULTURA BRASIL, 2018).
}

O Chefe indígena não compreende como o homem branco consegue viver em suas cidades, como pode deixar de apreciar os pequenos momentos que a natureza proporciona em troca de um ar sujo, de barulho e de água poluída. Em suas simples palavras: 
Não se pode encontrar paz nas cidades do homem branco. Nem lugar onde se possa ouvir o desabrochar da folhagem na primavera ou o zunir das asas dos insetos. Talvez, por ser um selvagem que nada entende. O barulho das cidades é terrível para os meus ouvidos. E que espécie de vida é aquela em que o homem não pode ouvir a voz do corvo noturno ou a conversa dos sapos no brejo à noite? Um índio prefere o suave sussurro do vento sobre o espelho d'água e o próprio cheiro do vento, purificado pela chuva do meio-dia e com aroma de pinho. O ar é precioso para o homem vermelho, porque todos os seres vivos respiram o mesmo ar, animais, árvores, homens (CULTURA BRASIL, 2018).

$\mathrm{Na}$ famosa carta que o Chefe Seattle enviou ao presidente americano, ele coloca em dúvida se o homem branco é realmente capaz para gerenciar a natureza e seus recursos. Em um dos trechos ele não consegue compreender o porquê do consumo exacerbado, ou mesmo desnecessário, no caso, de bisões. Ele falou que os indígenas, ou peles vermelhas, só consomem aquilo que necessitam sem que tenha exagero ou mesmo desperdício de bens.

Em sua sabedoria, disse que, se continuasse com esse consumo exagerado, ele acabaria por destruir a si próprio. Pois, corretamente, se os animais desaparecessem, o próprio homem branco iria desaparecer. O mais interessante é que ele, o Chefe Seattle, deu as primeiras linhas de um conceito muito atual, conhecido como Pegada Ecológica.

\section{Pegada Ecológica}

Com o passar do tempo diversos conceitos foram sendo criados a respeito do meio ambiente. Porém, um deles foi desenvolvido no fim do século passado: o da Pegada Ecológica. Este conceito, amplamente aceito, estabelece um nível de consumo de recursos naturais e que a terra seja capaz de repô-lo.

O termo "pegada ecológica" foi criado pelos cientistas canadenses Mathis Wackernagel e William Rees em 1990 e hoje é internacionalmente reconhecido como uma das formas de medir a utilização, pelo homem, dos recursos naturais do planeta. A Pegada Ecológica está diretamente relacionada ao desenvolvimento sustentável, ou seja, ao uso racional e equitativo (com justiça social) dos recursos naturais. $O$ tema sustentabilidade vem sendo discutido periodicamente pela Organização das Nações Unidas (ONU) em reuniões com a participação de chefes de Estado de diversos países. O primeiro encontro ocorreu em 1972 em Estocolmo, Suécia, e o último, em junho de 2012 no Rio de Janeiro, Brasil (WWF, 2018).

Durante vários anos o ser humano sequer se preocupou com a capacidade que a natureza possui de se recompor. A população mundial era baixa e sempre havia terras a serem 
exploradas; os rios eram limpos, inclusive utilizados para lazer; as cidades eram arborizadas e a poluição atmosférica estava dentro do aceitável.

Com o crescimento populacional, em poucas décadas o número de pessoas mais que dobrou, a fronteira agrícola se expandiu e, consequentemente, exigindo cada vez mais dos recursos naturais. Foi aí que se passou a entender sobre a necessidade de determinada quantidade de hectare para a manutenção da qualidade de vida dos cidadãos, dentro do padrão de vida estabelecido por sua sociedade específica.

Outro fator importante é a existência de um limite para a exploração. Nem todos os lugares da terra são passíveis de tal uso. De acordo com Sirvinskas (2011), calcula-se que aproximadamente 13,4 bilhões de hectares globais podem ser utilizados para a produção agrícola. Não se deve focar somente nisso, mas também na capacidade biológica para a recuperação do próprio planeta: não se pode ultrapassar esse valor sob pena de tornar a terra improdutiva. O nível atual de consumo da humanidade, de acordo com o autor mencionado, atingiu a marca de 2,7 hectares por habitante.

Cada sociedade possui o seu padrão de consumo de habitante por hectare: os habitantes da América do Norte, com exceção do México, possuem um consumo de 7,9; já os europeus, de 5,4; os africanos, por sua vez, possuem uma pegada média de 1,4. Este é o paradigma mundial atual, se tivéssemos o padrão dos primeiros, a terra só possuiria capacidade de abrigar algo em torno de 1,4 bilhão de habitantes, marca há muito ultrapassada. Se nos valêssemos da pegada média dos africanos, a terra teria capacidade de abrigar mais de 9 bilhões de habitantes. Contudo, considerando a média atual de 2,7 hectares por habitante, só teríamos a capacidade de abrigar até 5 bilhões de pessoas. Para que toda população mundial fosse atendida, precisaríamos de aproximadamente 18 bilhões de hectares agricultáveis. Para atingir essa quantidade seria necessário um espaço equivalente a meia Terra.

A pegada ecológica é composta de vários fatores. Conforme a WWF (World Wide Fund for Nature), são seus componentes: a capacidade de sequestrar o carbono emitido por diversas fontes de poluição, a extensão da área de cultivo, a área destinada às pastagens, a quantidade de florestas necessárias para atender ao consumo básico da população, as áreas construídas e os estoques pesqueiros.

Observa-se a exigência da água por todos os componentes da pegada ecológica para sua implementação e manutenção: as cidades precisam de água potável para suprir as necessidades de seus habitantes; pastos; agricultura, etc. Entretanto, esse elemento está se 


\section{O IMPACTO DA NOVA ESTAÇÃO DE TRATAMENTO DE EFLUENTES DO MUNICÍPIO \\ DE RESENDE-RJ PARA O FORTALECIMENTO DO CONCEITO DE CIDADE \\ SUSTENTÁVEL}

tornando cada vez mais escasso devido ao uso inadequado e despejo de efluentes não tratados muito acima da capacidade de absorção. O planeta clama por sustentabilidade!

\section{4 Água como fonte de vida para a sociedade}

Há uma ideia errônea de que o Brasil possui a maior reserva hídrica do mundo, porém os recursos hídricos mundiais estão se tornando cada vez mais escassos. É certo que aproximadamente $13,7 \%$ de toda água doce mundial encontra-se aqui, contudo, como bem observa Milaré (2007):

\footnotetext{
Não se pode deixar de considerar que nem toda ela é acessível ou mesmo potável para consumo. Havia no passado uma ideia equivocada de que as águas eram um bem de recurso ilimitado. Todavia, já ficou bastante evidenciado de que é limitado. Conforme Sirvinskas, "os recursos hídricos abrangem as águas superficiais, subterrâneas, os estuários e o mar territorial.
}

Sabe-se que a água é essencial à sobrevivência do ser humano, logo, não é possível imaginar a vida sem ela, no entanto, é importante salientar que a quantidade de água desde a última era glacial permanece a mesma. A água disponível para consumo humano e outras atividades é, aproximadamente, 0,0002\%. Considerando que a população mundial tem aumentado significativamente, a água a ser utilizada para manter a população, desde a agricultura para prover alimentos e até mesmo a atividade industrial continua sendo a mesma quantia.

O grande risco que a humanidade está passando é a de que seu emprego e, principalmente, seu desperdício, tem sido de forma exacerbada. Estudos atuais demonstram que a quantidade de água contaminada ou mesmo perdida em trajeto já está ultrapassando a destinada ao consumo humano.

A contaminação das águas vem se tornando alarmante. Esgotos têm sido despejados de forma irresponsável e, como consequência direta, o surgimento de doenças, que, teoricamente, seriam fáceis de serem controladas se tornou maior. O ministro do Superior Tribunal de Justiça (STJ) Herman Benjamin escreveu, em 1999, na Revista de Direito Ambiental, a preocupação quanto à contaminação das águas, nos seguintes termos: 
$\mathrm{Na}$ ótica internacional, chama a atenção a destruição acelerada e comprovada da floresta tropical que cobre a bacia do rio Amazonas (floresta latifoliada equatorial). Infelizmente, a crise ambiental por que passa o país não se resume, nem geográfica, nem qualitativamente, à Amazônia. Mais impiedosa e extensa tem sido a derrubada da Mata Atlântica e do Cerrado, ecossistemas extremamente ricos em diversidade biológica. No outro extremo da problemática, a poluição do ar, do solo e das águas põe em risco a saúde de milhões de brasileiros e ameaça processos ecológicos endêmicos e vitais (REVISTA DE DIREITO AMBIENTAL, 1999).

A qualidade da água é um fator importante para a sobrevivência do ser humano. Os governos brasileiros em todos os níveis não se conscientizam a respeito do tratamento dos efluentes gerados pela população de seus municípios, que deve ser constante. Porém, devido à falta de políticas públicas neste setor o nível de poluição dos rios é alarmante.

Sirvinskas (2011) chamava atenção para o despejo dos mais diversos produtos nos rios do país sem qualquer tratamento. Chama a atenção para o rio Paraíba do Sul, o qual se insere no tema da presente pesquisa:

\begin{abstract}
Além do rio Tietê, citamos, a título ilustrativo, o rio Paraíba do Sul, dentre muitos outros. Esta bacia abrange três Estados, 180 municípios e 5,5 milhões de habitantes e está morrendo aos poucos pelo despejo de um bilhão de litros de esgoto doméstico por dia e 150 toneladas de efluentes industriais, aliado ao assoreamento e aos portos de areia clandestinos que se multiplicam pelas suas margens.
\end{abstract}

Em outro momento, o autor alerta para as consequências advindas do tratamento inadequado e o uso indiscriminado de produtos à base de fósforo, potássio e matéria orgânica, quando alerta:

\footnotetext{
Outra causa da poluição hídrica é a eutrofização das águas superficiais e subterrâneas. Tal fenômeno consiste no enriquecimento com nutrientes de plantas, principalmente fósforo e nitrogênio, que são despejados de forma dissolvida ou particulada em lagos, represas e rios e transformados em partículas orgânicas, matéria viva vegetal, pelo metabolismo das plantas. Tal fato resulta no crescimento excessivo de aguapé (Eichhorniacrassipes) ou alface-d'água (Pistiastratiotes), que são as plantas aquáticas superiores mais comuns nesse processo, em regiões tropicais e subtropicais (SIRVINSKAS, 2011).
}

As Nações Unidas advertem para a quantidade de cidadãos que não possuem acesso à água potável: milhares podem morrer em consequência de doenças provenientes do uso de águas não tratadas. Neste contexto, Sirvinskas (2011) faz um alerta de que uma parte considerável da população, mesmo em termos regionais, não possuem água tratada para o consumo. 
A Conferência Internacional sobre Água e Desenvolvimento Sustentável realizada em Paris, em 1998, constatou que um quarto da população mundial não tem acesso a água potável, mais de $50 \%$ da população mundial carece de saneamento básico (esgoto) e a baixa qualidade da água e a falta de higiene figuram entre as causas de enfermidades e morte. Calcula-se que $33 \%$ dos óbitos são causados por problemas atinentes à qualidade dos recursos hídricos, nos países em desenvolvimento (grifo nosso).

Outra repreensão notável é a respeito de animais criados para fornecer alimentos ao homem e que disputam água potável para sua sobrevivência - ainda que mais efêmera do que poderia ser - e seus dejetos que, em uma quantidade considerável, não são tratados convenientemente e acabam, por fim, chegando aos rios por meio das chuvas.

Diversos problemas ocorreram com rios que abastecem cidades importantes. $\mathrm{Na}$ página da BBC Brasil é possível ver que cidades sofreram devido a derramamento de produtos ou subprodutos de mineração, bem como a cidade de Mariana-MG, onde o distrito inteiro de Bento Quirino foi tragado pela lama da mineração. Ao chegar ao rio Doce, que abastece diversas cidades da região, provocou um colapso no abastecimento de água potável, pois tornou suas águas imprestáveis para o consumo. Em outro caso emblemático do total descaso com o tratamento dos efluentes, vê-se no sítio do "O Eco" (2018), quando em Pernambuco, um matadouro jogava as carcaças, sangue e partes não aproveitáveis de bovinos diretamente no rio Jaboatão, o que pode ter ocasionado a atração de mais tubarões junto à costa das cidades pernambucanas, tendo sido proibido o uso de diversas praias na região metropolitana do Recife.

\section{Cidade Sustentável}

Sobre o assunto em comento, o Ministério do Meio Ambiente (MMA) criou a política nacional de resíduos sólidos e, nesta, estabelece que deve ser dado um tratamento adequado a esses resíduos. Tal tratamento torna as cidades ambientalmente corretas e com um melhor reaproveitamento dos recursos necessários para a sua manutenção, conforme se verifica no texto abaixo:

A correta destinação dos resíduos sólidos é condição primordial para uma cidade sustentável. A Política Nacional de Resíduos Sólidos (PNRS), aprovada em agosto de 2010, trouxe importantes instrumentos para que municípios de todo o Brasil iniciassem o enfrentamento aos principais problemas ambientais, sociais e econômicos decorrentes do manejo inadequado dos resíduos sólidos. A PNRS tem 
como pilar o princípio da responsabilidade compartilhada. Isso significa que indústrias, distribuidores e varejistas, prefeituras e consumidores são todos responsáveis pelos resíduos sólidos e cada um terá de contribuir para que eles tenham uma disposição final adequada. Buscar um melhor ordenamento do ambiente urbano primando pela qualidade de vida da população é trabalhar por uma cidade sustentável. Melhorar a mobilidade urbana, a poluição sonora e atmosférica, o descarte de resíduos sólidos, eficiência energética, economia de água, entre outros aspectos, contribuem para tornar uma cidade sustentável (MINISTÉRIO DO MEIO AMBIENTE, 2018).

A Agência Nacional de Águas (ANA), em conjunto com o Ministério das Cidades, elaborou um documento intitulado "Atlas Esgotos", onde apresenta o nível, a qualidade de tratamento dos efluentes e seus despejos nos corpos hídricos adjacentes aos municípios.

O ATLAS Esgotos é o resultado de um trabalho conjunto, desenvolvido sob a coordenação da Agência Nacional de Águas (ANA) em parceria com a Secretaria Nacional de Saneamento Ambiental do Ministério das Cidades (SNSA/MCidades) e com a colaboração de instituições federais, estaduais e municipais de todo o Brasil. Trazendo o olhar da gestão dos recursos hídricos, reúne e apresenta informações, diagnósticos e propostas de soluções para todas as 5.570 sedes municipais do País, amparados na avaliação da situação da coleta e tratamento dos esgotos e do impacto do lançamento desses efluentes nos corpos hídricos, com uma visão sistêmica por bacia hidrográfica. As propostas de soluções foram elaboradas para o horizonte de 2035, com foco na proteção dos recursos hídricos, no seu uso sustentável para depuração de efluentes urbanos e na racionalização dos investimentos (ANA, 2017).

Da análise desta publicação chega-se à conclusão de que a quantidade de esgoto coletado e tratado no país é menor do que a mundialmente aceitável. No site da própria Agência vê-se que a quantidade de dejetos despejados nos rios "in natura" corresponde a mais da metade. Entretanto, existem soluções individuais que minoram esta estatística, que são as fossas sépticas. O restante é totalmente incompatível com o que se pode considerar uma coleta adequada e tornar possível uma cidade melhorar a qualidade de vida de seus habitantes. Vê-se logo na página inicial daquela publicação:

No Brasil, $43 \%$ da população possui esgoto coletado e tratado e $12 \%$ utilizam-se de fossa séptica (solução individual), ou seja, 55\% possuem tratamento considerado adequado; $18 \%$ têm seu esgoto coletado e não tratado, o que pode ser considerado como um atendimento precário; e $27 \%$ não possuem coleta nem tratamento, isto é, sem atendimento por serviço de coleta sanitária (ANA, 2017).

Tal despejo sem saneamento básico é capaz de contaminar os recursos hídricos, tornando-os, praticamente, inservíveis para a coleta e consumo da população nas cidades. Em uma cidade sustentável diversos fatores se apresentam e a tornam com maior ou menor qualidade de vida e um dos principais está a falta de tratamento adequado aos efluentes. 


\title{
6 Obrigação de tratar os dejetos como fonte de sustentabilidade das cidades
}

O Ministério da Saúde alerta na publicação "Saneamento Básico" sobre a relação entre a falta deste e as diversas doenças que podem acometer a população, nos seguintes termos:

\begin{abstract}
Grande parte dos problemas sanitários que afetam a população mundial está intrinsecamente relacionada com o meio ambiente. Um exemplo disso é a diarreia, que, com mais de 4 bilhões de casos por ano (OPAS, 1998), é a doença que mais aflige a humanidade. Dentre as causas dessa doença destacam-se as condições inadequadas de saneamento. No Brasil, males como cólera, dengue, esquistossomose, tracoma, febre tifóide e leptospirose são exemplos disso (MANUAL DE SANEAMENTO, 2004).
\end{abstract}

Como se pode ver, a falta de tratamento correto dos efluentes e seu despejo diretamente nos rios causam diversas doenças endêmicas como as supracitadas no relatório do Ministério da Saúde.

O capítulo 18 da Agenda $21^{1}$ do Ministério do Meio Ambiente estabelece as bases para uma cidade sustentável e, desta forma, o saneamento básico é fundamental para que as cidades em desenvolvimento possam estabelecer padrões de vida adequados para a realidade da população e erradicação das doenças causadas pela falta de saneamento básico adequado.

18.47. Uma oferta de água confiável e o saneamento ambiental são vitais para proteger o meio ambiente, melhorando a saúde e mitigando a pobreza. A água salubre é também crucial para muitas atividades tradicionais e culturais. Estima-se que $80 \%$ de todas as moléstias e mais de um terço dos óbitos dos países em desenvolvimento sejam causados pelo consumo de água contaminada e, em média, até um décimo do tempo produtivo de cada pessoa se perde devido a doenças relacionadas com a água.

Com o intuito de se alcançar o objetivo proposto pelas Nações Unidas, nesta mesma agenda ficou estabelecido que as nações, de forma unilateral ou bilateral, deveriam implementar atividades que visassem eliminar os excrementos humanos por meio de coleta e tratamento adequado destes “(ii) Eliminação sanitária dos excrementos e do esgoto, usando sistemas adequados para tratar os resíduos líquidos em zonas urbanas e rurais”.

\footnotetext{
${ }^{1}$ A Agenda 21 pode ser definida como um instrumento de planejamento para a construção de sociedades sustentáveis em diferentes bases geográficas, que concilia métodos de proteção ambiental, justiça social e eficiência econômica.
} 
Os rios possuem um mecanismo natural de absorção desta carga de efluentes, mantendo suas águas em condições potáveis. Entretanto, há muito tempo as cidades despejam efluentes bem acima de sua capacidade de absorção e, como consequência imediata, há o surgimento de doenças que acabam afetando a população e seu desenvolvimento sustentável.

O próprio Ministério do Meio Ambiente, por meio do "Atlas Esgotos" apresenta a situação dos rios e a necessidade de elaboração de políticas públicas para a despoluição dos recursos hídricos naturais. A quantidade de água potável em condições de ser distribuída à população teve uma redução drástica, obrigando as empresas e cidades que tratam das águas a aumentarem a quantidade de produtos químicos que empregam para torná-la potável para o consumo nas cidades.

\section{Conceito e importância do saneamento básico}

Saneamento é o conjunto de medidas no intuito de preservar o meio ambiente, prevenir doenças e promover a saúde, melhorando, assim, a qualidade de vida da população e a produtividade do indivíduo. Ter saneamento básico é um fator primordial para o desenvolvimento de um país, pois os serviços de água tratada, coleta e tratamento de esgotos, ao melhorar a qualidade de vidas das pessoas, sobretudo na saúde infantil, reduzindo a mortalidade nos primeiros anos de vida, também acarreta melhorias na educação, na expansão do turismo, na valorização dos imóveis, na renda do trabalhador, na despoluição dos rios e preservação dos recursos hídricos.

De acordo com o Instituto Trata Brasil, uma Organização da Sociedade Civil de Interesse Público (OSCIP), formado por empresas com interesse nos avanços do saneamento básico e na proteção dos recursos hídricos do país, um estudo do Banco Nacional de Desenvolvimento Econômico e Social (BNDES) concluiu que $65 \%$ das internações em hospitais de crianças com menos de 10 anos foram provocadas por males oriundos da deficiência ou inexistência de esgoto e água limpa, que também surte efeito no desempenho escolar, pois crianças que vivem em áreas sem saneamento básico apresentam 18\% a menos no rendimento.

É cediço que o saneamento básico de qualidade é um fator preponderante para o desenvolvimento de uma nação, pois certamente irá refletir nos indicadores econômicos e sociais, trazendo benefícios para toda a sociedade. Apenas para ilustrar o benefício da ampliação do saneamento básico relativamente à educação, moradores de áreas que não têm acesso à rede de distribuição de água e de coleta de esgotos sofrem uma redução dos níveis Revista de Direito e Sustentabilidade | e-ISSN: 2525-9687 | Salvador | v. 4 | n. 1 | p. 19 - 38 | Jan/Jun. 2018 
escolares, acarretando perda de produtividade e, por consequência, de remuneração. Segundo o Instituto Trata Brasil (2017), somente o custo desse atraso escolar devido à falta de saneamento atingiu R \$ 16,6 bilhões para o país no ano de 2015.

De acordo com os dados fornecidos pelo Sistema Nacional de Informações sobre Saneamento $^{2}$ (SNIS, 2015), vinculado ao Ministério das Cidades, apenas 50,3\% da população brasileira tem coleta de esgoto. Em 2005, essa porcentagem era de 39,5\%, o que representou um total de 35,2 milhões de pessoas incluídas ao sistema de coleta. Concernente ao tratamento de efluentes o cenário é ainda pior, pois somente $43 \%$ do esgoto produzido recebe algum tipo de tratamento. Convém ressaltar que se trata de serviço público indispensável tanto para a preservação do meio ambiente como para a saúde das pessoas.

Levando-se em consideração a relevância do assunto, no período compreendido entre os dias 25 a 27 de setembro de 2015 foi realizada a Cúpula do Desenvolvimento Sustentável na sede da ONU em Nova Iorque, com o tema "Transformando Nosso Mundo: a agenda 2030 para o desenvolvimento sustentável”. Na ocasião foram definidos 17 (dezessete) objetivos de desenvolvimento sustentável e o de Número 6 está diretamente relacionado com o objeto da presente pesquisa: "Assegurar a disponibilidade e gestão sustentável da água e saneamento para todos até 2030".

Trata-se de uma meta ambiciosa, principalmente para o Brasil que, embora tenha registrado avanços nessa área nos últimos anos, apresenta índices de expansão do saneamento básico muito inferior quando comparado com outros países, como por exemplo, Alemanha, Inglaterra e Chile. Outra característica importante é a participação da iniciativa privada nas atividades de coleta e tratamento de esgotos, atingindo 94\% das Companhias no Chile, contra apenas 5\% no Brasil. Além disso, naquele país $98 \%$ do esgoto gerado recebe algum tipo de tratamento, contra $43 \%$ no Brasil.

A ilustração abaixo apresenta os dados comparativos de saneamento básico entre o Brasil e o Chile, demonstrando como ainda estamos distantes de atingir uma meta razoável em termos de coleta e tratamento de efluentes, atividades essenciais para a sustentabilidade dos municípios brasileiros e, consequentemente, para a manutenção do meio ambiente equilibrado.

\footnotetext{
${ }^{2} \mathrm{O}$ SNIS constitui-se no maior e mais importante sistema de informações do setor saneamento no Brasil, apoiando-se em um banco de dados que contém informações de caráter institucional, administrativo, operacional, gerencial, econômico-financeiro, contábil e de qualidade sobre a prestação de serviços de água, de esgotos e de manejo de resíduos sólidos urbanos.
} 




Figura 1 - Saneamento Básico Brasil x Chile

Fonte: Agência de Notícias CNI, 2017

Segundo o Plano Nacional de Saneamento Básico (PLANSAB) para o ano de 2033, uma de suas metas é dobrar o tratamento de esgotos no Brasil dos atuais $43 \%$ para $86 \%$, no entanto, seguindo o ritmo atual de investimentos, a universalização dos serviços seria atingida apenas em 2052, conforme se pode observar no gráfico abaixo (AGÊNCIA DE NOTÍCIAS CNI, 2017).
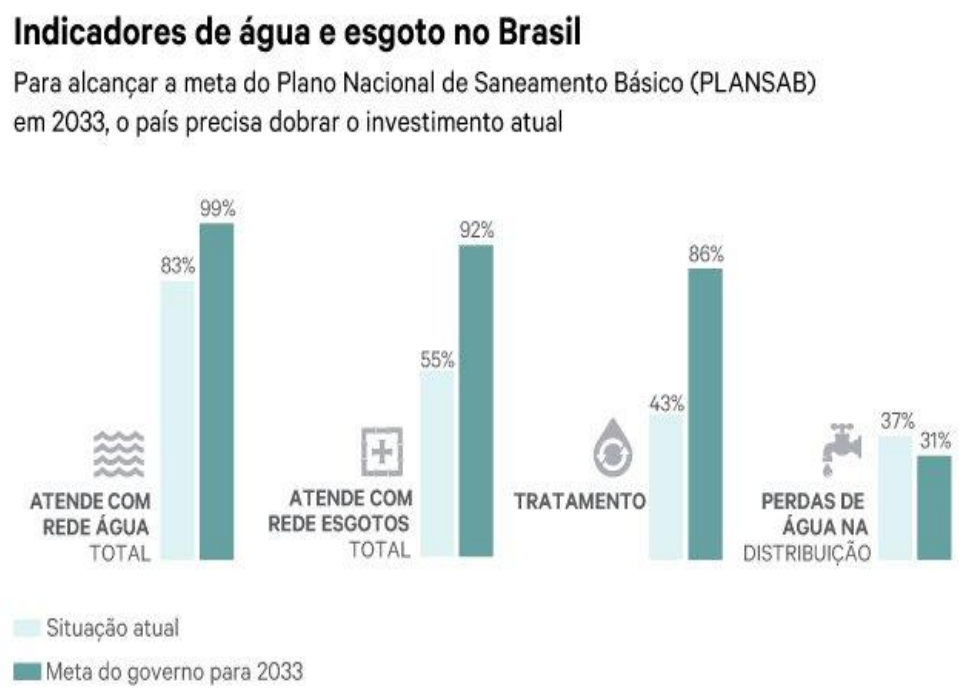

Fonte: Ministério das Cidades (2013) e SNIS (2015). Elaboração: GO Associados.

Figura 2 - Meta de tratamento de esgoto no Brasil para o ano de 2033

Fonte: Agência de Notícias CNI, 2017 


\section{Aspectos legais sobre o saneamento básico no Brasil}

Antes de adentrar especificamente no aparato legislativo acerca do saneamento básico no Brasil, é importante mencionar o fundamento constitucional a respeito da preservação do meio ambiente, previsto no artigo 225 da Constituição Federal, o qual estabelece que: "Todos têm direito ao meio ambiente ecologicamente equilibrado, bem de uso comum do povo e essencial à sadia qualidade de vida, impondo-se ao Poder Público e à coletividade o dever de defendê-lo e preservá-lo para as presentes e futuras gerações”.

Levando-se em consideração que a conquista do meio ambiente ecologicamente equilibrado também passa pelas ações do Poder Público nas áreas de tratamento da água e do esgoto, em 5 de janeiro de 2007 foi sancionada a Lei $\mathrm{n}^{\circ}$ 11.445, a qual estabelece as diretrizes nacionais para o saneamento básico e para a política federal de saneamento básico. Tal diploma normativo trouxe, como um de seus princípios, a universalização do acesso aos serviços públicos de abastecimento de água, esgotamento sanitário, limpeza urbana e manejo dos resíduos sólidos realizados de forma adequada à saúde pública e à proteção do meio ambiente.

$\mathrm{O}$ artigo $3^{\circ}$, inciso I, alínea " $\mathrm{b}$ " da citada lei estabeleceu o conceito de esgotamento sanitário, constituído pelas atividades, infraestruturas e instalações operacionais de coleta, transporte, tratamento e disposição final adequados dos esgotos sanitários, desde as ligações prediais até o seu lançamento final no meio ambiente, que acaba ocorrendo nas bacias hidrográficas.

Após dez anos da promulgação da Lei no 11.445/07, infelizmente, não há muito que comemorar a respeito das expectativas geradas pela novel legislação pois os avanços foram tímidos em matéria de saneamento básico, principalmente no que se refere ao tratamento de efluentes. Quando se compara a infraestrutura brasileira, os investimentos em saneamento apesar da sua importância na preservação do meio ambiente e para a saúde da população é inferior àqueles destinados para outros setores, como por exemplo, rodovias, aeroportos, energia e telecomunicações.

A Lei n ${ }^{\circ}$ 11.445/07 estabelece em seu art. 52 a atribuição ao Governo Federal, sob a coordenação do Ministério das Cidades, a responsabilidade pela elaboração do Plano Nacional de Saneamento Básico (PLANSAB), nos seguintes termos: 
Art. 52. A União elaborará, sob a coordenação do Ministério das Cidades:

I - o Plano Nacional de Saneamento Básico - PNSB que conterá:

a) os objetivos e metas nacionais e regionalizadas, de curto, médio e longo prazos, para a universalização dos serviços de saneamento básico e o alcance de níveis crescentes de saneamento básico no território nacional, observando a compatibilidade com os demais planos e políticas públicas da União;

b) as diretrizes e orientações para o equacionamento dos condicionantes de natureza político-institucional, legal e jurídica, econômico-financeira, administrativa, cultural e tecnológica com impacto na consecução das metas e objetivos estabelecidos;

c) a proposição de programas, projetos e ações necessários para atingir os objetivos e as metas da Política Federal de Saneamento Básico, com identificação das respectivas fontes de financiamento;

d) as diretrizes para o planejamento das ações de saneamento básico em áreas de especial interesse turístico;

e) os procedimentos para a avaliação sistemática da eficiência e eficácia das ações executadas.

O Plano Nacional de Saneamento Básico, quando aprovado em sua etapa final, constituirá o eixo central da política federal para o saneamento básico, promovendo a articulação nacional dos entes da federação para a execução das diretrizes da Lei $n^{\circ}$ 11.445/07. Será um instrumento orientador do Estado na condução da política pública de saneamento básico e da definição das metas e estratégias de governo para o setor nos próximos vinte anos, com vistas à universalização do acesso aos serviços de saneamento básico, contemplando o abastecimento de água potável, esgotamento sanitário, limpeza urbana e manejo de resíduos sólidos, e drenagem e manejo das águas pluviais urbanas (PORTAL SANEAMENTO BÁSICO, 2011).

\section{A nova Estação de Tratamento de Efluentes (ETE) da cidade de Resende-RJ}

Nos termos da Lei $n^{\circ}$ 11.445/17 toda cidade deve elaborar o Plano Municipal de Saneamento Básico (PMSB), exigindo, ainda, que a titularidade desse serviço público seja do município. No entanto, conforme prescreve o art. $8^{\circ}$ da citada lei, podem ser delegados à iniciativa privada a organização, a regulação, a fiscalização e a prestação desses serviços, conforme preceitua o art. 241 da Constituição Federal.

Seguindo essa tendência mundial, o município de Resende-RJ delegou a exploração do serviço público de saneamento básico à Concessionária Águas das Agulhas Negras em janeiro de 2008, período em que o tratamento de esgotos era de apenas $6 \%$ na cidade. Nesta época, 94\% dos efluentes eram despejados “in natura”no Rio Paraíba do Sul, considerado o mais importante da Bacia que leva o seu nome. 
Localizada na região mais desenvolvida e mais populosa do país, a Bacia do Rio Paraíba do Sul abrange 3 (três) estados da Federação: São Paulo, Minas Gerais e Rio de Janeiro, logo, possui grande importância socioeconômica, pois fornece água para as localidades em que está inserida, possibilidades de irrigação e geração de energia elétrica, beneficiando cerca de 14 milhões de pessoas residentes em 185 municípios. Daí a necessidade da sua preservação para as presentes e futuras gerações, conforme o ditame constitucional.

Neste contexto, no dia 4 de abril de 2017 foi inaugurada a nova Estação de Tratamento de Efluentes (ETE/AMAN ${ }^{3}$ ) da cidade de Resende. Construída em uma área de 29.600 (vinte e nove mil e seiscentos) metros quadrados cedida pela Academia Militar das Agulhas Negras, tem capacidade de tratamento de duzentos mil litros de esgoto por hora, beneficiando cerca de vinte e sete mil pessoas dos Bairros Paraíso, Alto Paraíso, Morro do Cruzeiro, Alambari, Castelo Branco e Cabral, além de todo o esgoto gerado na AMAN. O investimento da concessionária foi estimado em 6 milhões de reais, no entanto, o impacto positivo da obra será para o meio ambiente, contribuindo significativamente para a preservação do Rio Alambari, um dos principais afluentes do Rio Paraíba do Sul na região.

Com a inauguração da ETE/AMAN, a cidade de Resende alcançou o índice de 70\% de tratamento de todo o esgoto produzido no município. Trata-se de uma porcentagem significativa quando comparada com a realidade nacional, de apenas $43 \%$, segundo dados do Sistema Nacional de Informações sobre Saneamento, de 2015.

Apenas para exemplificar, neste estudo de 2015 o município brasileiro com a maior taxa de tratamento de efluentes foi a cidade de Jundiaí, no Estado de São Paulo, a qual apresentou um índice de 98,3\%, seguida pela cidade de Maringá, no Estado do Paraná, com 93,6\%, portanto, muito próximas de atingir a universalização em termos de saneamento básico (INSTITUTO TRATA BRASIL, 2015).

O método utilizado para o tratamento de efluentes na ETE/AMAN é o de lagoas de estabilização, que possui como características principais o baixo custo de manutenção e operação, sem perder em eficiência.

A ilustração abaixo representa a Estação de Tratamento com suas lagoas de estabilização. Ao fundo e à esquerda está o complexo da Academia Militar das Agulhas Negras e à direita os bairros beneficiados pela coleta e tratamento dos efluentes.

\footnotetext{
${ }^{3}$ A Academia Militar das Agulhas Negras é a instituição de ensino superior responsável pela formação dos oficiais combatentes de carreira do Exército Brasileiro.
} 
Percebe-se, ainda, a mata ciliar que envolve o Rio Alambari, o qual recebe todo o esgoto tratado antes de desaguar no Rio Paraíba do Sul. Aliás, uma das formas de se aferir a "saúde" de um rio é verificar a situação da mata ciliar que acompanha o seu curso, a qual desempenha uma função ambiental de extrema importância, tanto para a estabilidade do solo, quanto para a qualidade da água e desenvolvimento da biodiversidade. Neste sentido:

Em relação à manutenção da qualidade da água, a mata ciliar reduz o assoreamento e a força das águas que chegam aos rios, lagos e represas, o que mantém sua qualidade ao impedir a entrada de poluentes para o meio aquático. Além disso, formam corredores que contribuem para a conservação da biodiversidade, fornecendo alimento e abrigo para a fauna, constituindo barreiras naturais contra a disseminação de pragas e doenças da agricultura e, durante seu crescimento, absorvem e fixam dióxido de carbono, um dos principais gases responsáveis pelas mudanças climáticas (OPERSAN, 2015).



Figura 3 - Estação deTratamento de Efluentes/AMAN

Fonte: Concessionária Águas das Agulhas Negras, 2017

O tratamento de esgotos constitui-se em uma das mais importantes ações de sustentabilidade de um município, colaborando para a preservação do meio ambiente por meio do descarte de efluentes com um nível de pureza que não poluam as bacias hidrográficas, essenciais para o fornecimento de água para a população de uma cidade.

Embora não seja uma atividade que agrade aos políticos de plantão, pois as obras relacionadas ao saneamento básico normalmente ficam abaixo do solo e não aparecem para os cidadãos, as substâncias presentes no esgoto doméstico são extremamente prejudiciais aos 
mananciais, pois a matéria orgânica depositada pode acarretar a diminuição da concentração de oxigênio provocando a morte de peixes e outros organismos aquáticos, além de prejudicar o desenvolvimento de espécies vegetais que protegem os rios do assoreamento, causador de enchentes que atormentam as pessoas residentes nas proximidades dos rios.

\section{CONCLUSÃO}

O presente trabalho teve por finalidade analisar o impacto da nova estação de tratamento de efluentes da cidade de Resende-RJ para o fortalecimento do conceito de cidade sustentável e para a preservação do meio ambiente, bem de uso comum de todos.

Como se sabe, o saneamento básico na sua vertente coleta e tratamento de efluentes é somente uma parcela do que seria realmente uma cidade sustentável, que envolve também a qualidade do ar, a coleta e reciclagem do lixo urbano, utilização de fontes renováveis de energia e até mesmo a manutenção de áreas verdes, dentre outras.

A fim de se atingir o objetivo proposto, partiu-se da necessidade de apresentar os conceitos de consciência ecológica e pegada ecológica, este último internacionalmente reconhecido como uma das formas de medir a utilização, pelo homem, dos recursos naturais, portanto, relacionado com o desenvolvimento sustentável.

A seguir, foi feita uma análise da obrigação de tratar os dejetos como fonte de sustentabilidade das cidades, no contexto do capítulo 18 da Agenda 21 do Ministério do Meio Ambiente, o qual estabelece as bases para que uma cidade seja considerada sustentável.

Nos dois próximos tópicos foram colacionados o conceito e a importância do saneamento básico para a saúde da população, bem como os aspectos legais sobre o saneamento básico no Brasil, ressaltando o aparato normativo que regulamenta estas ações.

Por fim, e como parte principal deste trabalho, foi realizado um estudo a respeito da nova Estação de Tratamento de Efluentes (ETE) da cidade de Resende-RJ, demonstrando a preocupação com a sustentabilidade do município.

Com menos da metade da população atendida por rede de esgoto, o Brasil ainda engatinha no sentido da universalização dos serviços de saneamento básico prevista para o ano de 2033, em conformidade com o Plano Nacional de Saneamento Básico. Neste sentido, é de se comemorar quando um município, preocupado com a questão ambiental e com a saúde 
da população, investe seus recursos em ações concretas de ampliação da sua capacidade no tratamento de efluentes.

Levando-se em consideração que a água é um recurso natural cada vez mais escasso, seja pelo crescimento populacional, com aumento da demanda, seja pela redução da oferta, principalmente pela poluição dos mananciais, os serviços de saneamento básico como a coleta e o tratamento dos esgotos gerados pela população deve ser prioridade para os agentes públicos.

Ao atingir o percentual de $70 \%$ de tratamento dos efluentes, o município de Resende tem demonstrado a importância do saneamento básico para a saúde da população, bem como contribuído para a preservação do meio ambiente, essencial para a sadia qualidade de vida, no entanto, para atingir a universalização desse serviço ainda há muito trabalho pela frente, logo, torna-se necessário que os agentes da administração se conscientizem e continuem investindo os recursos necessários para se atingir esse objetivo no mais curto prazo possível.

\section{REFERÊNCIAS}

AGÊNCIA DE NOTÍCIAS CNI. Países eficientes em saneamento básico têm ampla participação de companhias privadas, mostra estudo da CNI. Disponível em: <http://www.portaldaindustria.com.br/agenciacni/noticias/2017/02/paises-eficientes-emsaneamento-basico-tem-ampla-participacao-de-companhias-privadas-mostra-estudo-da-cni> . Acesso em: 22 mar. 2018.

AGÊNCIA NACIONAL DE ÁGUAS. Atlas Esgotos. Disponível em: <http://www.snirh.gov.br/portal/snirh/snirh-1/atlas-esgotos> . Acesso em: 21 mar. 2018.

BBC BRASIL. O que já se sabe sobre o impacto da lama de Mariana? Disponível em: $<$ http://www.bbc.com/portuguese/noticias/2015/12/151201_dados_mariana $>$. Acesso em: 27 mar. 2018.

BENJAMIN, Antônio Herman V. Introdução ao Direito Ambiental Brasileiro in Revista de Direito Ambiental: RDA, v. 4, n. 14, abr./jun. 1999.

BRASIL. Constituição Federal de 1988. Disponível em: <http://www.planalto.gov.br/ccivil_03/constituicao/constituicaocompilado.htm>. Acesso em: 20 mar. 2018.

Lei $\mathbf{n}^{\circ}$ 11.445/2007 - Estabelece diretrizes nacionais para o saneamento básico; altera as Leis $\mathrm{n}^{\circ} 6.766$, de 19 de dezembro de 1979, 8.036, de 11 de maio de 1990, 8.666, de 21 de junho de 1993, 8.987, de 13 de fevereiro de 1995; revoga a Lei $n^{\circ} 6.528$, de 11 de maio de 1978; e dá outras providências.. Disponível em: <http://www.planalto.gov.br/ccivil_03/leis/L7210.htm>. Acesso em: 20 mar. 2018.

CONCESSIONÁRIA ÁGUAS DAS AGULHAS NEGRAS. Disponível em: 
<http://www.grupoaguasdobrasil.com.br/aguas-agulhasnegras/a-concessionaria>. Acesso em: 22 mar. 2018.

CULTURA BRASIL. A Carta do Cacique Seattle, em 1855. Disponível em:<http://www.culturabrasil.org/seattle1.htm>. Acesso em: 21 mar. 2018.

INSTITUTO NACIONAL DE PESQUISAS ESPACIAIS. Pegada Ecológica. Disponível em: <http://www.inpe.br/noticias/arquivos/pdf/Cartilha\%20-\%20Pegada\%20Ecologica\%20\%20web.pdf $>$. Acesso em: 20 mar. 2018.

INSTITUTO TRATA BRASIL. O que é saneamento e sua importância. Disponível em: <http://www.tratabrasil.org.br/saneamento/o-que-e-saneamento>. Acesso em: 20 mar. 2018.

Benefícios que o saneamento básico pode trazer. Disponível em:

<http://www.tratabrasil.org.br/blog/2017/08/10/5-beneficios-que-o-saneamento-basico>. Acesso em: 20 mar. 2018.

MACHADO, Paulo Affonso Leme. Direito Ambiental Brasileiro. 12. ed. atual. e ampl. São Paulo: Malheiros, 2004.

MILARÉ, Édis. Direito do Ambiente: a gestão ambiental em foco: doutrina, jurisprudência, glossário. 6. ed. rev., atual. e ampl. São Paulo: Editora Revista dos Tribunais, 2009.

MINISTÉRIO DA SAÚDE. Manual de Saneamento.3. ed. Disponível em: <http://bvsms.saude.gov.br/bvs/publicacoes/saneamento.pdf>. Acesso em: 20 mar. 2018.

MINISTÉRIO DO MEIO AMBIENTE. Cidades sustentáveis. Disponível em: <http://www.mma.gov.br/cidades-sustentaveis>. Acesso em: 28 mar. 2018.

O ECO. No rastro do sangue. Disponível em: <http://www.oeco.org.br/reportagens/1192oeco_12925/>. Acesso em: 27 mar. 2018.

OPERSAN SOLUÇÕES AMBIENTAIS. A importância da mata ciliar para a proteção das águas. Disponível em: <http://info.opersan.com.br/mataciliareaprotecaodasaguas>. Acesso em: 28 mar. 2018.

ORGANIZAÇÃO DAS NAÇÕES UNIDAS - Agenda 21. Disponível em: <http://www.onu.org.br/rio20/img/2012/01/agenda21.pdf>. Acesso em: 28 mar. 2018.

PORTAL SANEAMENTO BÁSICO. Disponível em:

<https://www.saneamentobasico.com.br/sp-plano-nacional-de-saneamento-basico-plansab>. Acesso em: 22 mar. 2018.

SIRVINSKAS, Luis Paulo. Manual de Direito Ambiental. 11 ed. atual. e ampl. São Paulo: Saraiva, 2011.

SISTEMA NACIONAL DE INFORMAÇÕES SOBRE SANEAMENTO. Disponível em: <http://www.snis.gov.br>. Acesso em: 20 mar. 2018. 
WWF - World Wide Fund for Nature .O que compõe a pegada? Disponível em: <https://www.wwf.org.br/natureza_brasileira/especiais/pegada_ecologica/o_que_compoe_a_ pegada>. Acesso em: 17 mar. 2018. 